\title{
PENGUATAN KELOMPOK DAN INTRODUKSI TEKNOLOGI REPRODUKSI DI KELOMPOK TANI TERNAK KERBAU WARNASARI KECAMATAN PLERED KABUPATEN CIREBON
}

\author{
Rini Widyastuti, ${ }^{1,2}$, Deru R.Indika ${ }^{3}$, Mas Rizky A.A. Syamsunarno ${ }^{4,5}$, dan Dwi Cipto Budinuryanto ${ }^{1}$ \\ ${ }^{1}$ Departemen Produksi Ternak, Fakultas Peternakan, Universitas Padjadjaran, \\ ${ }^{2}$ Program Studi Kedokteran Hewan, Fakultas Kedokteran, Universitas Padjadjaran, \\ ${ }^{3}$ Fakultas Ekonomi dan Bisnis, Universitas Padjadjaran, \\ ${ }^{4}$ Departemen Ilmu Kedokteran Dasar Fakultas Kedokteran, Universitas Padjadjaran, \\ ${ }^{5}$ Program Studi Bioteknologi Sekolah Pasca Sarjana, Universitas Padjadjaran \\ E-mail: r.widyastuti@unpad.ac.id
}

\begin{abstract}
ABSTRAK. Populasi kerbau di kelompok Tani Ternak Kerbau Warnasari Kecamatan Plered Kabupaten Cirebon sekitar 328 ekor. Walaupun telah terbentuk kelompok tani di wilayah tersebut belum dapat berfungsi secara optimal karena belum terbentuk struktur organisasi serta masih minimnya dinamika di dalam kelompok tersebut. Permasalahan lain yang dihadapi kelompok tersebut adalah terus menurunnya populasi kerbau disebabkan oleh rendahnya tingkat reproduksi kerbau, keterbatasan memanajemen ternak kerbau dan minimnya pengetahuan tentang aplikasi teknologi reproduksi. Kegiatan Pengabdian Masyarakat ini dilaksanakan untuk penguatan kelompok budidaya kerbau, pengaktifan dinamika pada kelompok peternak kerbau, dan pengenalan teknologi reproduksi. Metode pengabdian yang dilakukan adalah melakukan pelatihan organisasi dan pengenalan teknologi reproduksi kepada kelompok ternak kerbau Warnasari. Kegiatan yang telah dilakukan penyuluhan dengan materi meliputi: penguatan organisasi kelompok tani dan. pengenalan teknologi reproduksi dalam beternak kerbau. Hasil yang dipeoleh adalah terbentuknya struktur organisasi dan meningkatnya pemahaman masyarakat dalam penerapan manajemen beternak kerbau seta aplikasi teknologi reproduksi untuk meningkatkan produktivitas kerbau.
\end{abstract}

Kata Kunci: kerbau; kelompok tani ternak; organisasi; teknologi reproduksi

ABSTRACT. The population of buffalo in the Warnasari District Plered Cirebon regency about 328. The group of farmers already formed in that area, but has not been function optimally because the structure has not been formed and still lack of dynamics within the group. The another problem is decreased buffalo population due to the low level buffaloer reproductive effeciency, limitations in managing buffaloes and lack of knowledge reproductive technology. The Community Service Activities is carried out to strengthen buffalo cultivation groups, activation of dynamics in the breeder groups and introduction of reproductive technology. The method of devotion is to conduct organizational training and introduction of reproduction technology to breeder group. Activities that have been carried out with the extension of materials include: strengthening the organization of farmer groups and introduction of reproductive technology in buffalo raising. The results obtained are the formation of organizational structure and the increasing understanding of the community in the application of buffalo raising farm management after the application of reproductive technology to improve the productivity of buffaloes.

Key words: Buffaloes; Group of breeder; Organization; Reproductive technology

\section{PENDAHULUAN}

Kerbau merupakan salah satu potensi plasma nutfah yang perlu dillestarikan. Keberadaan kerbau memiliki peranan penting dalam kehidupan sosial ekonomi masyarakat diantaranya adalah sebagai penghasil daging, kulit, ternak kerja dan sebagainya. Perkembangan ternak kerbau relatif statis bahkan menurun, sehingga diperlukan upaya dan perhatian serius dari pihak terkait untuk melestarikan ternak ini. Berdasarkan hasil Sensus Pertanian Badan Pusat Statistik RI Tahun 2011 sebanyak 1,3 juta ekor mengalami penurunan menjadi 1,1 juta ekor pada Sensus Pertanian Badan Pusat Statistik RI Tahun 2013. Provinsi Jawa Barat merupakan salah satu sentra kerbau di Indonesia. Populasi kerbau di Provinsi Jawa Barat mencapai 113.869 ekor pada Tahun 2014.

Populasi ternak kerbau di Kabupaten Cirebon mencapai 4.214 ekor. Kerbau jantan sebanyak 876 ekor, betina 3.338 ekor. Jenis kerbau yang ada di Kabupaten Cirebon adalah lumpur (Bubalus bubalis). Sebagaimana daerah lain, populasi kerbau di Kabupaten Cirebon juga mengalami penurunan. Hal ini disebabkan oleh adanya masalah-masalah yang kompleks yang sangat berpengaruh dalam peningkatan populasi ternak kerbau di Kabupaten Cirebon (Effendi. A, 2007). Menurut data dari Dinas Pertanian, Perkebunan, Peternakan dan Kehutanan hingga saat ini terdapat 12 KTTK (Kelompok Tani Ternak Kerbau) di Kabupaten Cirebon. Mengalami penurunan bila dibandingkan data dari dinas yang sama tahun 2007 sebanyak 24 kelompok. Pola pemeliharaan kerbau di Kabupaten Cirebon dikonsentrasikan dengan sistem pengembangan kandang kawasan. Salah satu KTTK yang ada di Kabupaten Cirebon adalah KTTK Warnasari yang berlokasi di Desa Tegalsari Kecamatan Plered. Populasi ternak kerbau pada kelompok ini sebanyak 294 ekor dengan jumlah peternak anggota kelompok sebanyak 41 orang.

Pada umumnya, seorang peternak memelihara 10 ekor kerbau, namun rata-rata mereka hanya memiliki 1-3 ekor dan sisanya adalah milik pengusaha yang dipelihara dengan sistem gaduh. Populasi tersebut mengalami penurunan dari tahun ke tahun. Hal ini disebabkan oleh 
rendahnya tingkat reprodusi kerbau yang mereka pelihara. Kelompok peternak telah terbentuk namun demikian, kelompok tersebut belum dapat berfungsi karena belum terbentuk struktur organisasi yang sesuai dengan tugas dan fungsinya masing-masing. Mereka beternak kerbau secara tradisional dengan cara semi intensif dan kurang memperhatikan manajemen pemeliharaan kerbau yang baik karena minimnya pengetahuann yang mereka miliki. Masalah utama yang mereka hadapi adalah kesulitan air, kekurangan pangan pada musim kemarau dan tingginya kasus inbreeding. Inbreeding disebabkan oleh perkawinan kerbau yang masih dilakukan secara tradisional dan tidak ada identifikasi pejantan yang digunakan. Dampak inbreeding adalah penurunan kulaitas genetik pada kerbau yang mereka miliki, hal ini ditandai dengan kejadian albino dan genetic defect (tanduk melengkung) ke bawah, serta kerdil (Warriach et al., 2015).

Berdasarkan pengamatan, fungsi dari KTTK tersebut kurang maksimal untuk men-support perkembangan populasi kerbau di Kabupaten Cirebon, terbukti dengan masih awamnya pengetahuan anggota terhadap manajemen pemeliharaan dan teknologi reproduksi. kegiatan difokuskan pada penguatan kelompok dan peningkatan pengetahuan peternak tentang manajemen beternak kerbau dan pentingnya penerapan bioteknologi reproduksi untuk meningkatkan produktivitas peternak. Tujuan dari program pengabdian kepada masyarakat ini adalah untuk menggalakkan program Inseminasi Buatan pada ternak kerbau di KTTK Warnasari sehingga dapat meningkatkan mutu genetik dan populasi kerbau di kelompok tersebut.

\section{METODE}

Pengabdian ini dilaksanakan di Desa Tegalsari, Kecamatan Plered Kabupaten Cirebon Jawa Barat. Desa ini merupakan pemekaran dari DesaTegalwangi pada tahun 1982. Desa ini sebelah timur berbatasan dengan Desa Kaliwulu, sebelah Utara berbatasan dengan Desa Cangkring, sebelah Barat berbatasan dengan Desa Gombang dan sebelah selatan adalah Desa Tegalsari. Secara umum desa ini terkenal dengan kerajinan rotan dan batik. Meskipun begitu, pekerjaan di desa ini mayoriras adalah petani dan peternak. Oleh karena itu, sasaran kelompok pengabdian ini adalah Kelompok Ternak Wanasari.

Kegiatan Pengabdian Pada Masyarakat ini dititikberatkan pada pembinaan kelompok dan peningkatan pengetahuan peternak kerbau terhadap manajemen pemeliharaan dan aplikasi teknologi reproduksi. Target kegiatan ini adalah:

1. Pembinaan kelompok, pembentukan struktur dan penguatan dan pengelolaan organisasi pada kelompok peternak

2. Meningkatkan pemahaman peternak terhadap manajemen pemeliharaan pengenalan teknologi reproduksi, Meningkatkan ketikutsertaan seluruh anggota kelompok dalam introduksi teknologi reproduksi
Kegiatan dilakukan dalam dua bentuk yaitu demplot tugas dan tugas masing-masing pengurus kelompok. Peningkatan pemahaman peternak dilakukan dengan melakukan penyuluhan.

\section{HASIL DAN PEMBAHASAN}

\section{Penguatan kelompok peternak kerbau Warnasari Kecamatan Plered}

Selama ini para petani berternak kerbau secara konvensional dan dilakukan secara mandiri oleh masingmasing keluarga, petani melakukan perawatan sepenuh hati karena ternak sangat penting artinya untuk keluarga petani. Ternak merupakan tabungan hidup yang dapat membantu memenuhi kebutuhan rumah tangga bahkan untuk keperluan sekolah serta usaha. Selama ini karena dilakukan secara konvensional dengan pengetahuan yang terbatas, pendapatanpun sesuai dengan siklus lahir dan pertumbuhan ternak, tidak ada percepatan penambahan populasi ataupun penggemukkan (Munir. B, 2001).Namun saat ini petani peternak kerbau sudah mulai berkelompok. Kelompok dilihat sebagai upaya untuk melaksanakan kegiatan bersama dan untuk tujuan yang sama pula., Kelompok tani adalah kumpulan petani/peternak/pekebun yang dibentuk atas dasar kesamaan kepentingan, kesamaan kondisi lingkungan (sosial, ekonomi, sumberdaya) dan keakraban untuk meningkatkan dan mengembangkan usaha anggota.

Kesadaran petani akan pentingnya berkelompok dalam usaha meningkatkan kuantitas dan kualitas ternak kerbau semakin meningkat. Melalui Kegiatan pengabdian ini terbentuklah organisasi kelompok pada peternak kerbau wanasari. Meskipun struktur organisasi masih dasar, yakni hanya ada Ketua (Yani), Sekretaris (Ramya) dan Bendahara (Sutiya), dengan jumlah anggota kelompok sebanyak 50 orang. Meskipun baru terbentuk, namun petani yang tergabung dalam ternak kerbau sangat antusias dalam mendengarkan materi yang disampaikan, selain struktur dasar keorganisasian, petani kerbau juga perlu mempertegas benang merah antara rencana definitif kelompok dan rencana definitif kebutuhan kelompok sesuai dengan Pedoman Pembinaan Kelembagaan Petani yang terdiri atas Penumbuhan dan Pengembangan Kelompok Tani dan gabungan Kelompok Tani, karena harus ada penyusunan rencana definitif kelompok tani (RDK) dan rencana definitif kebutuhan kelompok (RDKK). Kelompok tanpa rencana yang jelas, maka akan mempengaruhi keberadaan kelompok tersebut secara kelembagaan, apa lagi rencana ini harus dibangun bersama anggota, agar anggota merasa memiliki dan mau membangun bersama untuk kepentingan yang sama pula (Andarwati et al., 2012).

Peningkatan pengetahuan peternak tentang manajemen beternak kerbau dan penerapan bioteknologi reproduksi dalam beternak kerbau. 
Peningkatan pengetahuan peternak tentang manajemen dan aplikasi bioteknologi reproduksi pada kerbau dilakukan dengan melakukan penyuluhan di rumah ketua Kelompok Tani Ternak Warna Sari. Penyuluhan dilakukan dalam dua tahap yaitu pada bulan Oktober dan November 2016. Penyuluhan dihadiri oleh seluruh anggota kelompok dengan narasumber drh. Dwi Cipto Budinuryanto yang menyampaikan materi tentang aplikasi manajemen beternak kerbau dan drh. Rini Widyastuti menyampaikan materi tentang aplikasi teknologi repoduksi pada peternakan kerbau. Pre test dan post tes dilkuakn dengan memberikan kuisioner untuk mengukur peningkatan pengetahuan tentang aplikasi manajemen beternak dan aplikasi teknologi reproduksi pada peternakan kerbau. Pre test diberikan kepada peserta sebelum penyuluhan dimulai, sedangkan post tes diberikan setelah kegiatan penyuluhan dilakukan. Berdasarkan penyebaran kuisioner, hasil yang dicapai meningkatnya pemahaman peternak tentang manajemen beternak kerbau. Sesuai dengan hasil FGD dan Penyuluhan manajemen dan praktek baik pemeliharaan kerbau (Good Management Practices). Mengemukakan faktor pendukung dan penghambat adalah pengetahuan tentang manajemen dalam usaha ternak sendiri masih menjadi kendala, Dinamika kelompok dengan keterbatasan SDM masih harus membuat pengurus membina dan mencari pendamping untuk melakukan monitoring kelompok ternak. Selain itu masih ada kendala-kendala baik internal masing-masing individu serta masalah eksternal terkait jaringan dan peluang usaha terkait kemitraan yang ingin dikembangkan.

Proses terakhir, dimana petani ternak kerbau dijelaskan terkait tanda birahi dan pelaksanaan IB pada kerbau. Hal ini sangat penting, karena kadangkala petani sering abai situasi dan kondisi yang sedang terjadi pada ternaknya sendiri, karena kesibukkan mencari pakan sehingga terlupakan kondisi biologis hewan ternak itu sendiri. Dalam pengembangbiakan ternak kerbau Siklus berahi kerbau 21-24 hari. lama berahi 1,5 hari; umumnya terjadi pada malam hari. Adapun Tanda-tanda Berahi sama dengan sapi, lama bunting kerbau 310 hari (Lendhanie, 2005). Metode perkawinan dapat dilakukan secara kawin alam (menggunakan pejantan pemacek) dan inseminasi buatan (Sutama, I.K, 2008). Kegiatan memasukkan sperma ke dalam vagina ternak betina sehingga menyebabkan bunting. IB efektif jika dilakukan dengan mengikuti protap yang tepat mengingat dari satu ekor pejantan dapat menghasilkan sekitar perkawinan terhadap 20.000 induk betina per tahun, sedangkan dengan kawin alam, satu ekor pejantan hanya dapat digunakan untuk 200 - 300 perkawinan per tahun (Tambing et al., 2000).

Hasil dari FGD dan Penyuluhan tentang pengenalan terhadap teknologi reproduksi dan pentingnya penerapan teknologi reproduksi dalam beternak kerbau. Mengemukakan berbagai macam permasalahan yang berkaitan dengan masalah reproduksi pada kerbau seperti pengetahuan dan keahlian dalam IB sendiri masih harus didampingi lebih lanjut. Oleh karena itu upaya yang dilakukan perbibitan ternak kerbau yang dapat dilakukan di Desa Tegalsari Kecamatan Pleret kabupaten Cirebon antara lain :

1. Kelompok yang relatif masih baru biasanya menghadapi masalah permodalan, maka memperkuat modal usaha merupakan salah satu cara yang harus dilakukan, dimana dana dapat dilakukan secara swadaya atau bermitra dengan pihak lain

2. Selama ini ternak yang dikembangkan adalah bibit yang tidak tersertifikasi, artinya bibit dikembangkan secara konvensional. Maka perlu meningkatkan bibit yang unggul, pengembangan populasi, dan peningkatan produktifitas

3. Kelompok yang relatif baru ini, sedari awal perlu menarapkan prinsip kemandirian agar memiliki motivasi tim untuk sama-sama berkembang sesuai dengan tujuannya.

4. Selain kelompok ternak untuk pengembangbiakan, diperlukan unit kelompok yang khusus menangani pengembangan pembibitan yang tentunya dapat bekerjasama dengan mitra.

Secara kelembagaan, organisasi kelompokjuga perlu menetapkan rencana tindak lanjut dengan menetapkan target jangka pendek dan jangka panjang. Adapun strategi yang dapat dikembangkan menurut Peraturan Menteri Pertanian NOMOR: 273/Kpts/OT.160/4/2007 yaitu :

1. Strategi pengembangan SDM dan kelembagaan

2. Strategi peningkatan populasi dan produktivitas

3. Strategi pengembangan sarana, prasarana dan infrastruktur

4. Strategi pendekatan ekonomi dan kesejahteraan peternak. Dengan strategi tersebut secara kelembagaan kelompok tani bisa berkembang dan lewat IB produktivitas ternak kerbaulumpurbisamemungkinkan meningkatkan kesejahteraan petani.

5. Upaya lain, setelah secara kelembagaan kuat, dana tersedia, penguatan SDM juga terus berjalan untuk meningkatkan pengetahuan dan keahlian serta meningkatkan kesejahternaan anggota kelompok ternak itu sendiri.

\section{SIMPULAN}

Secara umum, anggota Kelompok Tani Ternak Warnasari sudah memiliki pengetahuan yang cukup tentang fungsi dan tugas masing-masing pengurus maupun anggota kelompok. Pembinaan kelompok tani Wanasari dalam mengembangkan ternak kerbau perlu dilakukan lebih intensif, terutama dalam menjalankan fungsi kelompok dan peningkatan produktivitas kerbau. Pengetahuan tentang manajemen pemeliharaan dan aplikasi teknologi reproduksi yang mereka miliki masih sangat terbatas dan pengetahuan dalam mengelola peternakan didapatkan secara turun temurun. Untuk meningkatkan efesiensi 
produksi dan reproduksi perlu peningkatan pengetahuan peternak tentang manajemen beternak kerbau dan penerapan bioteknologi reproduksi dalam beternak kerbau dan Pengenalan tanda berahi dan pelaksanaan IB pada kerbau.

\section{UCAPAN TERIMAKASIH}

Terimakasih kami ucapkan kepada DRPMI UNPAD yang telah memberikan dana PPM

\section{DAFTAR PUSTAKA}

Andarwati, S., Guntoro, B., Haryadi, F.T., Sulastri, E. (2012). Dinamika Kelompok Peternak Sapi Potong Binaan Universitas Gajah Mada di Propinsi Daerah Istimewa Yogyakarta. Sains Peternakan 10(1): 39-46.

Effendi A. (2007). Potensi Ternak Kerbau Di Kabupaten Cirebon. Seminar dan Lokakarya Nasional Usaha Ternak Kerbau..
Lendhanie, U.U. (2005). Karakteristik Reproduksi Kerbau Rawa Dalam Kondisi Lingkungan Peternakan Rakyat. Bioscientiae 2 (1):43-48.

Munir, B. (2001). Dinamika Kelompok, Penerapan Dana Laboratorium Ilmu Perilaku. Universitas Sriwijaya. Palembang

Sutama, I.K. (2008). Pemanfaatan Sumberdaya Ternak Lokal Sebagai Ternak Perah Mendukung Peningkatan Produksi Susu Nasional. Wartazoa 18 (4).

Tambing, S.N., Toelihere, M.R., Yusuf, T.L. (2000). Optimasi Program Inseminasi Buatan Pada Kerbau. Wartazoa $10(2)$.

Warriach, H. M., McGill, D.M., Bush, R.D., Wynn, P.C., Chohan, K.R. (2015). A Review of Recent Developments in Buffalo Reproduction - A Review Asian-Australas J Anim Sci 28(3): 451455. 